\title{
Extent of adoption of improved fish farming practices by the farmers in North-eastern region of India
}

\author{
A. K. SINGHA, A. K. TRIPATHI, P. C. JAT, R. BORDOLOI AND J. K. SINGHA* \\ ICAR-Agricultural Technology Application Research Institute, Zone-III, Umiam - 793 10, Meghalaya, India \\ *Karimganj College, Karimganj - 788 710, Assam, India \\ e-mail: arunkumar_singha@yahoo.co.in
}

\begin{abstract}
This study, to analyse the extent of adoption of improved fish farming practices by the farmers, was conducted in 13 purposively selected districts having Krishi Vigyan Kendras (KVKs) in the north-eastern region of India with 130 samples each from KVK adopted and non-adopted villages respectively through proportionate random sampling technique. Data from selected respondents were collected with the help of pre-tested structured schedule through personal interview method. The study revealed that majority of the respondents in KVK adopted villages had medium level of adoption of improved fish farming practices, while over half of the total respondents in non-adopted villages showed poor adoption level of the same fish farming practices. Specific practices like recommended size of ponds for pond management, bottom raking for pond preparation and maintenance of adequate dissolved oxygen concentrations in ponds to prevent fish stress were found to have little/no adoption among both categories of respondents.
\end{abstract}

Keywords: Extent of adoption, Fish farming, KVK, North-eastern region

With the changing consumption pattern, emerging market forces and technological developments, fisheries sector in India has made rapid strides in recent years and assumed added importance through a rapid transformation. Fisheries sector contributes to the national income, exports, food and nutritional security as well as employment generation. It is a principal source of livelihood for a large section of economically underprivileged population of the country, especially in the coastal areas. Fishing as an occupation is being practised in India since time immemorial and has been regarded as a supplementary enterprise of the fishermen community on the subsistence level with little external inputs (Mruthyunjaya, 2004).

The north-eastern region of India is mostly hilly and only about $30 \%$ area is plain on both sides of the river Brahmaputra and Barak, which lies between 21.57 to $29.3^{\circ}$ north latitudes and 84.46 to $97.3^{\circ}$ east longitudes. This area receives highest rainfall during the prolonged rainy season from March to October. As a result, aquatic resources in the form of rivers, streams, lakes, reservoirs, bheels, swamps and ponds are vast and varied in the region. The hypsographic profile and the river systems of the region reveal rich repository of aquatic resources that have great potential for fisheries development. There has been wide variation in the number of fishes reported from this region ranging from 172 to 267 (Sen, 2000). The region has vast potential for fish production, both cold and warm water fisheries and the people are interested in culture as well as capture fisheries. Despite such rich resource potential for fish production, the region is lagging behind in its exploitation and management due to biotic, abiotic and socio-economic constraints and is lagging behind in fish production (Saha and Nath, 2013). A substantial part of the resources in this region still remain unutilised/unavailable and presently fish is imported from other states like Andhra Pradesh, Bihar, Uttar Pradesh and West Bengal to meet increasing demand.

The fisheries resource of the region comprises of three important river basins viz., Brahmaputra, Barak and their tributaries. It has been recognised that the region needs special attention because of its strategic location and fragile eco-systems. In order to maintain balance between regional identity of the population and pace of development, it seems appropriate to adopt latest technologies based on local inputs and skills. Fishery if developed on scientific lines will go a long way in contributing to the rural economy in remote hilly areas of the region. This becomes specially important for initiation with available exotic and indigenous fishes as the resource base in the context of rising environmental concerns (Vass, 2005). Notwithstanding these proven benefits, the adoption of aquaculture technologies have been found often neglected among the farmers as income generating 
and livelihood security means in the region. The crucial link to improve fish production by the resource poor farmers is effective transfer of fish farming innovations to them (Singas and Manus, 2014). However, this sector also did not receive adequate attention from the social scientists to understand its various socio-economic dynamics. Of late, however, attention has been directed towards the crucial role of fish farmers in the sustainable production and management of fisheries in various states of the region. Past research experiences show that the adoption-rejection decision of the farmer is, to a larger extent, dependent on the degree of risk involved relative to the existing practices including the socio-economic characteristics of farmers including their social, physical and cultural environments and a picture of exactly where the farmer fits (Jones, 1987) in fish farming. In this backdrop, the present study was undertaken to evaluate the extent of adoption of improved fish farming practices by the farmers in villages adopted/non-adopted by Krishi Vigyan Kendras (KVKs).

The study was conducted during 2012-14 in 13 districts purposively selected in the north-eastern region of India comprising eight states. Only those districts in the region having KVKs for past 15 years with full strength of scientific staff and infrastructural facilities were selected for the study (Table 1). A pre-tested well structured schedule comprising all aspects of personal and socio-economic variables of the respondents as well as mandated activities such as demonstrations, training programmes and other extension activities conducted by KVKs were prepared for data collection from the respondents. Any farmer who has been directly associating or receiving help and technical support from KVKs in carrying out improved fish farming activities in his own farming system on regular basis for last fifteen years was considered as respondent for the study. Similarly, farmers from non-adopted village from each selected district, practicing fish farming with no/ least technical support and assistance from the KVK were also considered as respondents.

From the 13 selected districts of the region (i.e., Assam-4, Arunachal Pradesh-1, Manipur-1, Meghalaya-1, Nagaland-1, Mizoram-2, Tripura-2 and Sikkim-1), two villages, one adopted village and one non-adopted village were selected from each district. On consultation with the available records of the KVK as well as local leaders and extension workers, a list of fish farmers representing two different categories was prepared for each village. From the individual list of fish farmers from each village, ten fish farmer respondents each from adopted and non-adopted village were randomly selected, which formed 20 respondents (10 beneficiary and 10 non-beneficiary) from each district. Thus a total of 260 farmer respondents (130 beneficiary and 130 non-beneficiary) were finally selected for data collection from 13 districts of the region.

The independent variables viz., age, education, caste, family type and family size were measured with the help of scales developed by Trivedi and Pareek (1964). The variables viz., primary occupation, annual income, size of operational land holding, type of primary farming activities, farming experience, trainings received, mass media exposure and extension contact were measured with the help of schedules structured for the study.

Extent of adoption of improved fish farming practices was operationally defined as the level of adoption of recommended fish farming practices by the respondents in their farming system. To determine the extent of adoption, improved fish farming practices were listed out and a schedule consisting of questions against each selected practice was administered to the intended respondents in a 4 point Likert type scale (Likert, 1932) namely; "fully", "partially" and "not adopted", with scores as 3, 2, 1 and 0 respectively. For the purpose of analysis, the mean

Table 1. State and host institute-wise distribution of selected KVKs with more than 15 years of functioning under Zone-III (up to IX Five Year Plan)

\begin{tabular}{|c|c|c|c|}
\hline State & KVK & Host Institute & Year of establishment \\
\hline Assam & Cachar & Assam Agricultural University & 1994 \\
\hline Assam & Golaghat & Assam Agricultural University & 1994 \\
\hline Assam & Kokrajhar & Assam Agricultural University & 1985 \\
\hline Assam & Sonitpur & Assam Agricultural University & 1979 \\
\hline Arunachal Pradesh & West Siang & ICAR Research Complex for NEH Region & 1979 \\
\hline Manipur & Imphal West & ICAR Research Complex for NEH Region & 1979 \\
\hline Meghalaya & West Garo Hills & ICAR Research Complex for NEH Region & 1979 \\
\hline Nagaland & Dimapur & ICAR Research Complex for NEH Region & 1979 \\
\hline Mizoram & Kolasib & Dept. of Agriculture, Research and Education, Govt. of Mizoram & 1979 \\
\hline Mizoram & Lunglei & Dept. of Agriculture, Research and Education, Govt. of Mizoram & 1994 \\
\hline Sikkim & East Sikkim & ICAR Research Complex for NEH Region & 1982 \\
\hline Tripura & South Tripura & ICAR Research Complex for NEH Region & 1984 \\
\hline Tripura & West Tripura & Sri Ram Krishna Seva Kendra, Kolkata & 1979 \\
\hline
\end{tabular}


adoption scores were calculated separately for each of the practice as well as for overall practices. Finally, on the basis of scores obtained, the respondents were classified into 3 categories by following the procedure as adopted by Gupta (1989).

Data collection from randomly selected respondents was carried out using a pre-tested "structured schedule" through personal interview method followed by group discussion. For this purpose, an interview schedule was constructed for data collection from the respondents in the light of the objectives of the study. The selected respondents were personally approached and interviewed at their place of residence/field by the investigators along with the scientific staff of the concerned KVK and their responses were carefully recorded.

Table 2 indicates that as many as $43.85 \%$ respondents in adopted villages were found to have medium level adoption of improved fisheries practices followed by low $(38.46 \%)$ and high $(17.69 \%)$ respectively. The finding is in conformity with that of the study in Mizoram conducted by Rahman (2007) in case of livestock farming practices. While more than half of the respondents $(54.62 \%)$ in non-adopted villages observed low adoption of improved farming practices followed by medium (40\%) and high (5.38\%) respectively. Mean difference of 5.67 between beneficiary and non-beneficiary respondents clearly shows that respondents in adopted villages had better adoption of fisheries practices than non-beneficiary respondents.

Table 3 discloses that specific recommendations like eradication of aquatic weeds, eradication of unwanted fishes, lime application during pond preparation, stocking of indigenous species and avoiding excess feeding, were found adopted by all the respondents $(100 \%)$ in adopted villages. While all the respondents $(100 \%)$ in non-adopted villages had adopted only three recommendations such as: (i) eradication of aquatic weeds (under reclamation of old ponds), (ii) stocking of indigenous species and (iii) stocking of exotic species. Notwithstanding the practice-wise extent of adoption, the specific recommendations in fish farming adopted by over three-fourths of the beneficiary and non-beneficiary respondents were: depth for grow-out pond and seed raising pond (93.85 and $82.31 \%$ ), productive water conditions ( 83.31 and $76.92 \%$ ), complete dewatering (92.31 and 84.61\%), removal of excess muck (84.61 and $84.61 \%$ ), repairing of side slopes while removing muck (90 and 79.23\%) and hygienic condition (92.31 and $85.38 \%$ ) respectively.

With regard to the extent of adoption of the selected practices, the table further reveals that recommended practices were found to have relatively higher level of adoption by the beneficiary farmers than that of non-beneficiary farmers as shown by their corresponding total scores viz., depth for grow-out pond and nursery (267) under pond requirement; eradication of aquatic weeds (302), eradication of unwanted fishes (288) and complete dewatering (263) and repairing of side slopes while removing muck (260) under reclamation of old ponds; lime application (270) and pond fertilisation (226) under pond preparation; stocking density (264) and time for stocking under stocking; feed storage in well ventilated and dry bins (210) under feeding and test netting (219) and prophylactic and curative measures (231) under health care. The results also reveal that none of the respondents in both categories of villages was found to adopt recommendations like toxicity test and maintenance of adequate dissolved oxygen concentrations in ponds to prevent fish stress.

It is concluded from the present study that some of the practices although very important in terms of potential growth of different species of fishes, were poorly adopted by majority of the respondents. Technologies with complicated components and those which required more time and labour were difficult for farmers to adopt. The study further revealed that due to various scientific and innovative approaches taken up by KVKs in study areas, most of the farmers in adopted villages had better practical knowledge and skills on different practices which aided in higher adoptions. Proper technical guidance through systematic extension efforts including specific demonstration and training programmes should be organised on regular basis by the concerned line departments and other stakeholders including KVKs so that farmers could exploit the opportunities provided to their advantage by practicing fish farming innovations

Table 2. Extent of adoption of fishery practices by the farmers in adopted and non-adopted villages

\begin{tabular}{|c|c|c|c|c|c|c|c|c|}
\hline \multirow{3}{*}{ Category } & \multirow{3}{*}{ Score range } & \multicolumn{6}{|c|}{ Distribution of respondents } & \multirow{3}{*}{ Mean difference (Score value) } \\
\hline & & \multicolumn{3}{|c|}{ Adopted village $\left(\mathrm{n}_{1}=130\right)$} & \multicolumn{3}{|c|}{ Non-adopted village $\left(\mathrm{n}_{2}=130\right)$} & \\
\hline & & $\mathrm{f}$ & $\%$ & Mean \pm S.D. & $\mathrm{f}$ & $\%$ & Mean \pm S.D. & \\
\hline Low & $<28.80$ & 50 & 38.46 & $38.68 \pm 9.88$ & 71 & 54.62 & $33.01 \pm 9.26$ & 5.67 \\
\hline Medium & $28.80-48.56$ & 57 & 43.85 & & 52 & 40.00 & & \\
\hline High & $>48.56$ & 23 & 17.69 & & 7 & 5.38 & & \\
\hline Total & & 130 & 100.00 & & 130 & 100.00 & & \\
\hline
\end{tabular}


Table 3. Practice-wise extent of adoption of improved fisheries practices by the farmers

\begin{tabular}{|c|c|c|c|c|c|c|c|c|c|c|c|c|}
\hline \multirow{3}{*}{ Practice } & \multicolumn{12}{|c|}{ Distribution of respondents $\left(\mathrm{n}_{1}=130, \mathrm{n}_{2}=130\right)$} \\
\hline & \multicolumn{2}{|c|}{$\begin{array}{l}\text { Great } \\
\text { extent (3) }\end{array}$} & \multicolumn{2}{|c|}{$\begin{array}{r}\text { Significant } \\
\text { extent (2) }\end{array}$} & \multicolumn{2}{|c|}{$\begin{array}{l}\text { A little } \\
\text { extent (1) }\end{array}$} & \multicolumn{2}{|c|}{$\begin{array}{c}\text { Not at all } \\
(0)\end{array}$} & \multicolumn{2}{|c|}{ Total adoption } & \multicolumn{2}{|c|}{ Total score } \\
\hline & $\overline{\mathrm{AV}}\left(\mathrm{f}_{1}\right)$ & $\operatorname{NAV}\left(f_{2}\right)$ & $\overline{A V}\left(n_{1}\right)$ & $\operatorname{NAV}\left(\mathrm{n}_{2}\right)$ & $\overline{\mathrm{AV}}\left(\mathrm{n}_{1}\right)$ & $\operatorname{NAV}\left(\mathrm{n}_{2}\right)$ & $\overline{\mathrm{AV}}\left(\mathrm{n}_{1}\right)$ & $\operatorname{NAV}\left(n_{2}\right)$ & $\mathrm{AV}\left(\mathrm{n}_{1}\right)$ & $\operatorname{NAV}\left(\mathrm{n}_{2}\right)$ & $\mathrm{AV}\left(\mathrm{n}_{1}\right)$ & $\operatorname{NAV}\left(\mathrm{n}_{2}\right)$ \\
\hline $\begin{array}{l}\text { Site selection } \\
\text { (based on soil type, topography, } \\
\text { watershed, water table and safety) }\end{array}$ & 13 & 4 & 50 & 41 & 37 & 45 & 30 & 40 & $100(76.92)$ & $90(69.23)$ & 176 & 139 \\
\hline $\begin{array}{l}\text { Pond requirements } \\
\text { i. Recommended size of ponds }\end{array}$ & 9 & 3 & 51 & 44 & 30 & 33 & 40 & 50 & $90(69.23)$ & $80(61.54)$ & 159 & 130 \\
\hline $\begin{array}{l}\text { ii. Depth for grow-out pond } \\
\text { and seed raising pond }\end{array}$ & 35 & 5 & 75 & 62 & 12 & 40 & 8 & 23 & $122(93.85)$ & $107(82.31)$ & 267 & 179 \\
\hline iii. Productive water conditions & 11 & 9 & 67 & 60 & 30 & 31 & 22 & 30 & $108(83.31)$ & $100(76.92)$ & 197 & 178 \\
\hline $\begin{array}{l}\text { Reclamation of old ponds } \\
\text { i. Eradication of aquatic weeds }\end{array}$ & 49 & 24 & 74 & 77 & 7 & 29 & 0 & 0 & $130(100.00)$ & $130(100.00)$ & 302 & 255 \\
\hline $\begin{array}{l}\text { ii. Eradication of unwanted } \\
\text { fishes }\end{array}$ & 41 & 24 & 76 & 72 & 13 & 30 & 0 & 4 & $130(100.00)$ & $126(96.92)$ & 288 & 246 \\
\hline iii. Complete dewatering & 38 & 22 & 67 & 64 & 15 & 24 & 10 & 20 & $120(92.31)$ & $110(84.61)$ & 263 & 218 \\
\hline $\begin{array}{l}\text { iv. Exposure of bottom to } \\
\text { bright sunlight after } \\
\text { dewatering }\end{array}$ & 14 & 6 & 58 & 43 & 36 & 31 & 32 & 50 & $98(75.38)$ & $80(61.54)$ & 194 & 135 \\
\hline v. Removal of excess muck & 22 & 13 & 68 & 66 & 20 & 31 & 20 & 20 & $110(84.61)$ & $110(84.61)$ & 222 & 202 \\
\hline $\begin{array}{l}\text { vi. Repairing of side slopes } \\
\text { while removing muck }\end{array}$ & 36 & 11 & 71 & 62 & 10 & 30 & 13 & 27 & $117(90.00)$ & $103(79.23)$ & 260 & 187 \\
\hline $\begin{array}{l}\text { Pond preparation } \\
\text { i. Bottom raking }\end{array}$ & 7 & 2 & 43 & 35 & 40 & 33 & 40 & 60 & $90(69.23)$ & $70(53.85)$ & 147 & 109 \\
\hline ii. Lime application & 26 & 17 & 88 & 67 & 16 & 40 & 0 & 6 & $130(100.00)$ & $124(95.38)$ & 270 & 225 \\
\hline iii. Pond fertilisation & 20 & 11 & 73 & 57 & 20 & 32 & 17 & 30 & $113(86.92)$ & $100(76.92)$ & 226 & 179 \\
\hline $\begin{array}{l}\text { Stocking } \\
\text { i. Indigenous species }\end{array}$ & 18 & 24 & 68 & 76 & 44 & 30 & 0 & 0 & $130(100.00)$ & $130(100.00)$ & 234 & 254 \\
\hline ii. Exotic species & 23 & 14 & 77 & 71 & 30 & 45 & 0 & 0 & $130(100.00)$ & $130(100.00)$ & 253 & 229 \\
\hline iii. Stocking density & 36 & 4 & 72 & 45 & 12 & 41 & 10 & 40 & $120(92.31)$ & $90(69.23)$ & 264 & 143 \\
\hline iv. Time for stocking & 23 & 3 & 70 & 32 & 10 & 27 & 27 & 68 & $103(79.23)$ & $62(47.69)$ & 219 & 100 \\
\hline v. Toxicity test & 0 & 0 & 0 & 0 & 0 & 0 & 130 & 130 & $0(0.00)$ & $0(0.00)$ & 0 & 0 \\
\hline $\begin{array}{l}\text { Feeding } \\
\text { i. Select high quality feed that } \\
\text { contain adequate nitrogen } \\
\text { and phosphorous }\end{array}$ & 3 & 0 & 27 & 15 & 68 & 35 & 32 & 80 & $98(75.38)$ & $50(38.46)$ & 131 & 65 \\
\hline $\begin{array}{l}\text { ii. Store feed in well ventilated } \\
\text { and dry bins }\end{array}$ & 24 & 5 & 55 & 43 & 28 & 41 & 23 & 41 & $102(78.46)$ & $89(68.46)$ & 210 & 142 \\
\hline $\begin{array}{l}\text { iii. Apply feed uniformly with a } \\
\text { mechanical feeder }\end{array}$ & 5 & 3 & 41 & 46 & 50 & 43 & 34 & 38 & $96(73.85)$ & $92(70.77)$ & 147 & 144 \\
\hline $\begin{array}{l}\text { iv. Don't apply more feed that } \\
\text { is well accepted by fish }\end{array}$ & 30 & 12 & 76 & 70 & 24 & 40 & 0 & 8 & $130(100.00)$ & $122(93.85)$ & 266 & 216 \\
\hline $\begin{array}{l}\text { v. Maintain adequate dissolved } \\
\text { oxygen concentrations in } \\
\text { ponds to prevent fish stress }\end{array}$ & 0 & 0 & 0 & 0 & 0 & 0 & 130 & 130 & $0(0.00)$ & $0(0.00)$ & 0 & 0 \\
\hline $\begin{array}{l}\text { Health care } \\
\text { i. Hygienic condition }\end{array}$ & 29 & 12 & 60 & 60 & 31 & 39 & 10 & 19 & $120(92.31)$ & $111(85.38)$ & 238 & 195 \\
\hline ii. Test netting & 11 & 2 & 23 & 33 & 36 & 15 & 60 & 80 & $70(53.85)$ & $50(38.46)$ & 115 & 87 \\
\hline $\begin{array}{l}\text { iii. Prophylactic and curative } \\
\text { measures }\end{array}$ & 23 & 6 & 67 & 56 & 28 & 29 & 12 & 39 & 118 (90.77) & $91(70.00)$ & 231 & 159 \\
\hline
\end{tabular}

Figures in parentheses indicate percentage; AV - Adopted village, NAV - Non-adopted village 
not only to improve income for their families but also to meet the growing demand for fish in the region. Formation of cooperative groups of fish farmers may facilitate easy access to credit. Specialised training in areas like on-farm feed formulation should be given to the farmers. Government should also provide storage and processing facilities for fish farmers as well as improved marketing facilities in the region particularly in hilly areas to enhance profitable and sustainable fish production from farming.

\section{Acknowledgements}

The study was carried out as an institutional project funded by ICAR-Agricultural Technology Application Research Institute (ATARI), Zone-III, Barapani, Meghalaya. The authors are grateful to all scientific and technical staff of KVKs under Zone-III who directly and indirectly assisted in selection of villages and data collection from the respondents.

\section{References}

Gupta, S. 1989. Diffusion of agricultural innovation in village India, Wiley Eastern Ltd., New Delhi.

Jones, D. 1987. World agricultural economics and rural sociology, Abstract, 19(3): 91.

Likert, Rensis 1932. A technique for the measurement of attitudes. Arch. Psychol., 140: 1-55.

Mruthyunjaya 2004. Strategies and options for increasing and sustaining fisheries and aquaculture production to benefit poor households in India, Research Project Report, National Centre for Agricultural Economics and Policy Research, New Delhi, India, 142 pp.

Rahman, S. 2007. Adoption of improved technologies by the pig farmers of Aizawl District of Mizoram, India. Livestock Res. Rural Dev., 19(1).

Saha, R. K. and Nath, D. 2013. Indigenous technical knowledge (ITK) of fish farmers at Dhalai District of Tripura, North-east India. Indian J. Tradit. Knowl., 12(1): 80-84.

Sen, N. 2000. Occurrence, distribution and status of diversified fish fauna of North-east India. In: Ponniah, A. G. and Sarkar, U. K. (Eds.), Fish germplasm inventories and conservation in North-east India, National Bureau of Fish Genetic Resources, Lucknow.

Singas, S. and Manus, P. 2014. Factors influencing adoption of pond fish farming innovations in Potsy of Morobe Province, Papua New Guinea. Universal J. Agric. Res., 2(6): 191-197.

Trivedi, G. and Pareek, U. 1964. Reliability and validity of a rural socio-economic status scale. Indian J. Appl. Psychol., 1(1): 34-40.

Vass, K. K. 2005. Coldwater fisheries in India - status and prospects. In: Tyagi, B. C., Shyam Sunder and Madan Mohan (Eds.), Cold water fisheries research and development in north-east region of India. National Research Centre on cold water fisheries, Indian Ccouncil of Agricultural Research, Bhimtal, India, p. 1-16. 